\title{
Potential Hormone Mechanisms of Bariatric Surgery
}

\author{
Georgios K. Dimitriadis ${ }^{1,2,3} \cdot$ Manpal S. Randeva ${ }^{1}$ - Alexander D. Miras ${ }^{2}$
}

Published online: 5 August 2017

(C) The Author(s) 2017. This article is an open access publication

\begin{abstract}
Purpose of Review In recent years, the role of the gastrointestinal (GI) tract in energy homeostasis through modulation of the digestion and absorption of carbohydrates and the production of incretin hormones is well recognized.

Recent Findings Bariatric surgery for obesity has been a very effective method in substantially improving weight, and numerous studies have focused on intestinal adaptation after bariatric procedures. A number of structural and functional changes in the GI tract have been reported postsurgery, which could be responsible for the altered hormonal responses. Furthermore, the change in food absorption rate and the intestinal regions exposed to carbohydrates may affect blood glucose response.

Summary This review hopes to give new insights into the direct role of gut hormones, by summarising the metabolic effects of bariatric surgery.
\end{abstract}

Keywords Bariatric surgery $\cdot$ Gastric banding $\cdot$ Sleeve gastrectomy $\cdot$ Roux-en-Y gastric bypass $\cdot$ Gut hormones $\cdot$

This article is part of the Topical Collection on Health Services and Programs

Georgios K. Dimitriadis

g.dimitriadis@warwick.ac.uk

1 Division of Translational and Experimental Medicine, Clinical Sciences Research Laboratories, University of Warwick Medical School, Coventry CV2 2DX, UK

2 Academic Division of Diabetes, Endocrinology and Metabolism, Imperial College London, Hammersmith Campus, London W12 ONN, UK

3 Division of Translational and Experimental Medicine-Metabolic and Vascular Health, Warwick Medical School, University of Warwick, Coventry CV4 7AL, UK
Gastrin · GLP-1 · GLP-2 · PYY · Ghrelin · CCK · GIP · Oxyntomodulin · Secretin · VIP · PP · Insulin · Glucagon · Somatostatin · Obestatin · Gustducin · FGF19 · FGF21

\section{Introduction}

Obesity, defined as a body mass index $\geq 30 \mathrm{~kg} / \mathrm{m}^{2}$, has become a worldwide epidemic, considered among the greatest public health challenges of our time. An estimated global progression of obesity over the next decades indicates that by 2030, more than 1 billion adults will be obese [1]. Obesity can contribute towards multiple cardiometabolic co-morbidities, with debilitating consequences. The weight reductive effects of bariatric surgery have been well documented over the past decades, and bariatric surgery remains currently the most effective weight loss method mainly by GI tract volume restriction and/or beneficial metabolic sequelae [2]. The mechanisms underlying the metabolic effects of bariatric surgery remain elusive, but they are likely to be secondary to changes in the secretion of gut hormones and the transformation of the gastrointestinal lining [3]. This review article aims at elucidating the potential hormone mechanisms of the most commonly used bariatric procedures (Table 1).

\section{Procedures}

Bariatric procedures, such as Roux-en-Y gastric bypass and vertical sleeve gastrectomy, cause substantial and durable weight loss in both humans and rodents. Lately, these surgical interventions have also been termed metabolic due to the substantive metabolic changes beyond body weight loss alone. The most popular interventions at present are gastric banding, sleeve gastrectomy and the Roux-en-Y gastric bypass. 
Table 1 The effects of the most common bariatric procedures on gut hormone regulation

\begin{tabular}{|c|c|c|c|}
\hline Hormone & $\mathrm{GB}$ & SG & RYGB \\
\hline Gastrin & $\rightarrow$ & & \\
\hline Ghrelin & & & \\
\hline CCK & - & 4 & \\
\hline GIP & - & & \\
\hline GLP-1 & $\rightarrow \hat{T}$ & 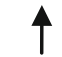 & \\
\hline GLP-2 & $\rightarrow$ & 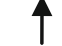 & \\
\hline PYY & $\rightarrow$ & 4 & 4 \\
\hline Oxyntomodulin & - & 一 & \\
\hline Secretin & - & 一 & \\
\hline VIP & - & 一 & - \\
\hline PP & $\rightarrow$ & 一 & \\
\hline Insulin & $\rightarrow \hat{\top}$ & $\uparrow$ & 4 \\
\hline Obestatin & - & $\downarrow$ & 4 \\
\hline Gustducin & - & 一 & 4 \\
\hline Somatostatin & - & 一 & - \\
\hline Glucagon & $\rightarrow$ & & \\
\hline FGF-19 & 个 & 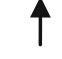 & $\Delta$ \\
\hline FGF-21 & - & $\downarrow$ & $\rightarrow$ \\
\hline
\end{tabular}

More than one arrow means that data are conflicting

$G B$ gastric banding, $S G$ sleeve gastrectomy, $R Y G B$ Roux-en-Y gastric bypass, $C C K$ cholecystokinin, $G I P$ glucose-dependent insulinotropic polypeptide, $G L P$-1 glucagon-like peptide 1, GLP-2 glucagon-like peptide 2, $P Y Y$ polypeptide YY, VIP vasoactive intestinal polypeptide, $P P$ pancreatic polypeptide, FGF19 fibroblast growth factor 19, FGF21 fibroblast growth factor $21, \rightarrow$ no change, $\downarrow$ decreased, $\uparrow$ increased, - unknown

\section{Gastric Banding}

Gastric banding (GB) includes the placement of a silicone ring around the stomach to create a small upper gastric pouch at the bottom of the oesophagus. This procedure was introduced in the 1970s and remains safe, well tolerated and efficacious with a relative low risk of serious complications. Another benefit to this procedure is the ability to adjust the band enhancing its weight loss effect without compromising safety [4].

\section{Roux-en-Y Gastric Bypass}

The Roux-en-Y gastric bypass (RYGB) is one of the most common bariatric procedures and has the greatest weight loss effect [5]. During the procedure, a small gastric pouch is created, draining into the jejunum (alimentary limb) causing nutrients to bypass the pylorus and duodenum. The bile and pancreatic juices drain into the duodenum and jejunum as normal (biliopancreatic limb) but are only mixed with food after the anastomosis of the alimentary and biliopancreatic limbs to create the common limb. 
The length of the common limb is an important factor for the development of serious complications [5]. In standard RYGB, the Roux limb is usually $0.75-1.5 \mathrm{~m}$ long with a common limb of $\sim 3 \mathrm{~m}$ which is usually adequate for absorption of nutrients. A modified version of the RYGB is called 'distal bypass' technique, reducing the length of the common limb to $\sim 75 \mathrm{~cm}$, carrying though a higher risk for complications [5].

\section{Sleeve Gastrectomy}

The sleeve gastrectomy (SG) involves creating a long, thin longitudinal gastric pouch or sleeve. This reduces the volume of the stomach by approximately $80 \%$ but leaves the pylorus intact. SG was initially performed as a precursor to a larger procedure but has been increasingly used alone due to its efficacy and safety. SG is now one of the most commonly performed bariatric surgery procedures with impressive weight loss effect and relative low rate of complications [6].

\section{Potential Hormone Mechanisms of Bariatric Surgery}

The metabolic effects of bariatric surgery have been attributed by many to changes in the secretion of gastroenteropancreatic peptides although additional mechanisms have been proposed
(Fig. 1). In this review article, we will focus on the weight loss-independent effects of bariatric surgery mainly involving changes in postprandial gut hormone secretions (Table 2) [3].

\section{Bariatric Surgery and Gut Hormones}

\section{Gastrin}

Gastrin is a peptide hormone that stimulates the secretion of gastric acid $(\mathrm{HCl})$ by the parietal cells of the stomach and aids in gastric motility. It is released by $\mathrm{G}$ cells in the pyloric antrum of the stomach, duodenum and the pancreas. Gastrin binds to cholecystokinin B receptors to stimulate the release of histamines in enterochromaffin-like cells, and it induces the insertion of $\mathrm{K}+\mathrm{H}+$ ATPase pumps into the apical membrane of parietal cells (which in turn increases $\mathrm{H}+$ release into the stomach cavity). Its release is stimulated by peptides in the lumen of the stomach and gastrin reduces appetite. Rather than being a single molecular entity, gastrin is actually a family of multiple peptides of varying lengths with varying degrees of biological activity. As one would expect, following RYGB, there is some evidence suggesting that postprandial gastrin levels fall after RYGB both in the first 2 weeks postoperatively [7•] and over the first year [8]. Recent evidence

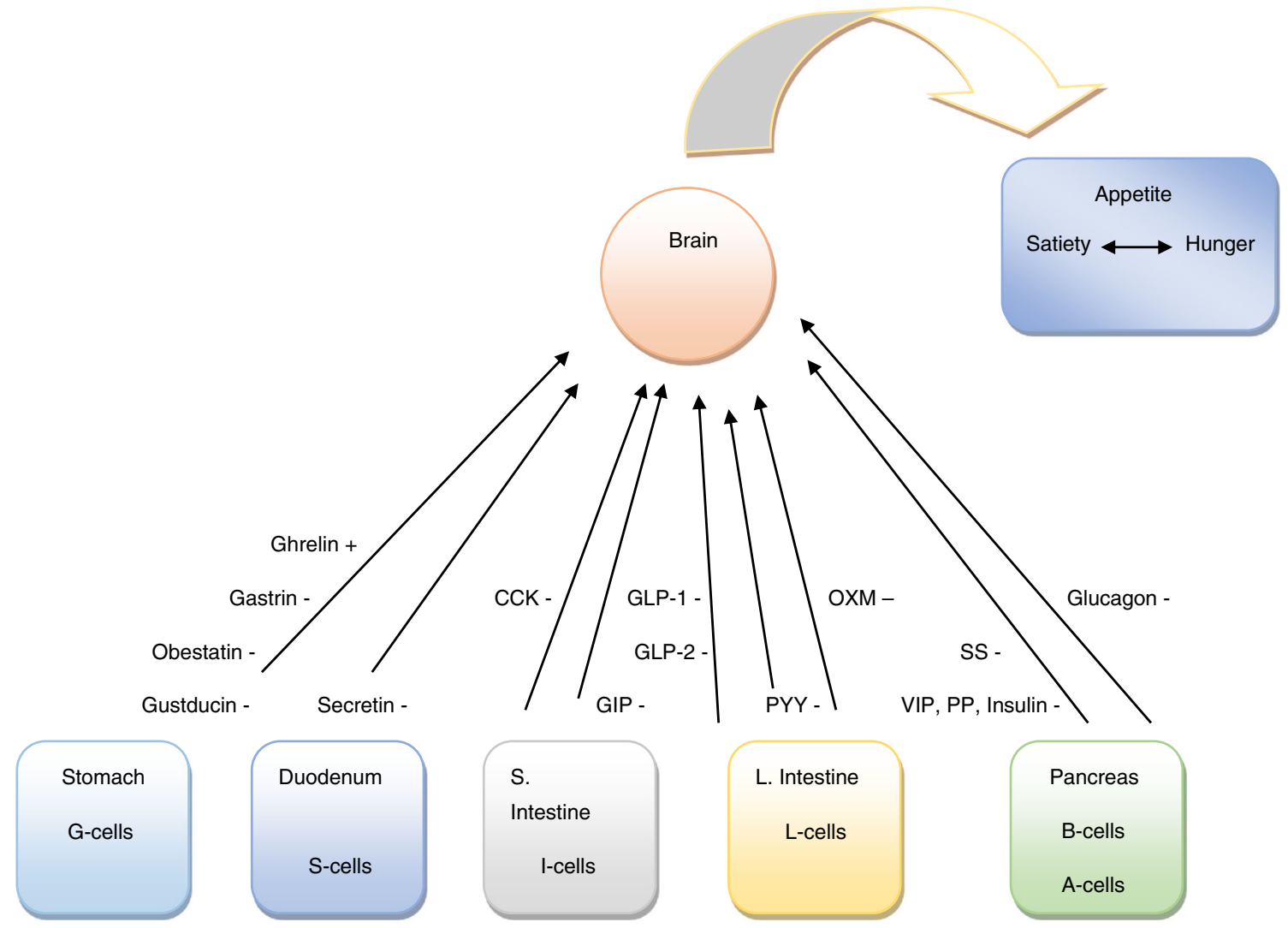

Fig. 1 Hormone interactions (feedback mechanisms) between the brain and organs of the gastrointestinal tract 
Table 2 Gut hormones and their actions

\begin{tabular}{|c|c|c|}
\hline Hormone & Organ/cell & Mechanism of action \\
\hline \multirow[t]{2}{*}{ Gastrin } & \multirow[t]{2}{*}{ Stomach/G cells } & Increases $\mathrm{HCl}$ production \\
\hline & & Promotes satiety \\
\hline \multirow[t]{2}{*}{ Ghrelin } & \multirow[t]{2}{*}{ Stomach/G cells } & Increases appetite \\
\hline & & Enhances gastric emptying GI motility and GH secretion \\
\hline \multirow[t]{2}{*}{ GLP-1 } & \multirow[t]{2}{*}{ Ileum $/ \mathrm{L}$ cells } & Causes the incretin effect \\
\hline & & Increases insulin sensitivity and production. Delays gastric emptying. Enhances satiety. \\
\hline GLP-2 & Ileum/L cells & Causes gut hypertrophy. Alters GI motility \\
\hline PYY & Colon/L cells & Delays gastric emptying. Promotes satiety \\
\hline OXM & Ileum/L cells & Promotes satiety, increases energy expenditure \\
\hline Secretin & Duodenum/S cells & Reduces gastric and duodenal motility. Enhances insulin release \\
\hline VIP & Enteric and parasympathetic nerves & $\begin{array}{l}\text { Promotes hormone secretion by the brain, gut and pancreas Increases the secretion of } \\
\text { water and electrolytes. Reduces } \mathrm{HCl} \text { secretion }\end{array}$ \\
\hline \multirow[t]{2}{*}{ PP } & \multirow[t]{2}{*}{ Pancreas- PP cells } & Promotes satiety \\
\hline & & Exocrine and endocrine secretion regulator \\
\hline Insulin & Pancreas/B cells & Regulates metabolism of carbs, fat and protein. Promotes absorption glucose from the blood \\
\hline Obestatin & Stomach/epithelial cells & Promotes satiety \\
\hline Gustducin & Stomach/specialized lining cells & Enhances GLP-1 secretion \\
\hline SS & Pancreas/D cells & Reduces gastrin, GLP-1, CCK, GIP and secretin \\
\hline Glucagon & Pancreas/A cells & Promotes glucogenolysis and gluconeogenesis \\
\hline FGF19 & Ileum & Regulation of glucose and lipid metabolism. Increases energy expenditure \\
\hline
\end{tabular}

suggests that the remnant stomach is subject to multiple histological changes following RYGB. One study demonstrated increased cell proliferation rate in the epithelium of the excluded gastric antrum coupled with a reduction in the number of $\mathrm{G}$ cells [9]. It has been suggested that excessive gastric acid production maybe involved in the pathogenesis of abnormal histological findings in the stomach after RYGB [10]. Grong et al. used a protein-rich mixed meal on a cohort of 20 female patients previously operated with RYGB or SG versus 13 female matched controls and were able to demonstrate diminished gastrin levels in the RYGB but no statistically significant changes between the SG group and controls [11]. A study of 24 patients following GB demonstrated no change in fasting gastrin concentrations 6-12 months after surgery [12]. Others have showed that SG may be associated with increased gastrin levels in both human and rodents $[13,14]$. The role of gastrin secretion as either a cause or a consequence of altered gastric histology remains unclear.

\section{Ghrelin}

Ghrelin is a peptide hormone produced by ghrelinergic cells in the gastrointestinal tract and functions as a neuropeptide in the central nervous system [15•]. Besides regulating appetite, ghrelin also plays a significant role in regulating the distribution and rate of use of energy [16]. Ghrelin is most active in its acylated form, with an octanoyl group attached to its third amino acid residue, which occurs due to the action of ghrelin- $O$-acyltransferase (GOAT). As a consequence, it activates the growth hormone secretagogue receptor (GHSR), which is predominantly found in the hypothalamus and pituitary glands [17]. Ghrelin levels rise with prolonged fasting and drop after ingestion of food, hence the poor long-term efficacy of diet for the management of obesity $[18 \cdot]$. The effect of bariatric procedures appears to have variable effects on ghrelin secretion, possibly due to the altered passage of ingested nutrients through the gastric fundus where the ghrelin-producing cells are predominantly located and additionally due to small sample size of the existing studies. Fruhbeck and co-workers studied 24 obese men following adjustable GB $(n=8)$, RYGB $(n=8)$ or lifestyle modifications [19, 20]. Six months after surgery, patients with GB and lifestyle group had similar ghrelin levels, whereas patients with RYGB had a significant decrease. Cummings et al. noted that gastric bypass $(n=5)$ was associated with a reduction in 24-h ghrelin area under the curve when compared to five healthy obese matched controls and ten controls of normal weight [19]. Dirksen et al. followed 33 patients for 12 months after RYGB and observed that greater weight loss was associated with a higher degree of ghrelin suppression postsurgically [21•]. Others, however, have demonstrated 
increased ghrelin levels in humans or rodents following RYGB $[22,23]$. On the other hand, SG may be associated with reduced ghrelin levels likely due to the removal of that part of stomach where ghrelin-secreting cell concentration is higher [24].

\section{Cholecystokinin}

Cholecystokinin (CCK) is a peptide hormone of the gastrointestinal system, synthesized and secreted by I cells in the duodenal mucosa being responsible for stimulating the digestion of fat and protein. Its presence causes the release of digestive enzymes and bile from the pancreas and gallbladder, respectively, slowing gastric emptying and also acting as a hunger suppressant. Several studies have shown an increase in CCK levels postprandially after RYGB in response to a mixed meal $[7 \bullet, 21 \bullet]$. CCK is primarily released in the presence of amino acids and fatty acids within the duodenum, which is excluded from contact with nutrients following RYGB in contrast with what studies have shown. Other factors of CCK release such as parasympathetic impulses and intraluminal releasing factors may be responsible for the increased levels of CCK following bariatric surgery [25]. The effect of bariatric surgery on CCK homeostasis still remains unclear. Few studies have examined the changes in $\mathrm{CCK}$ which occur following other bariatric procedures. Mans et al. showed that SG resulted in enhanced CCK levels and increased satiety in 8 morbidly obese patients versus 16 matched controls [26]. Peterli et al. [27•] studied patients for a year after RYGB or SG. SG was associated with a much larger CCK increase compared to the RYGB group. The effect of SG in CCK secretion was evident 1 week postoperatively and gained in magnitude over the first year [27•]. To date, there are no studies looking at the effect of GB on CCK concentration.

\section{Glucose-Dependent Insulinotropic Polypeptide}

Glucose-dependent insulinotropic polypeptide (GIP) is derived from a 153-amino acid proprotein encoded by the GIP gene and circulates as a biologically active 42 -amino acid peptide. It is synthesized by $\mathrm{K}$ cells, which are found in the mucosa of the duodenum and the jejunum of the gastrointestinal tract. Like glucagon-like peptide-1 (GLP-1), GIP is associated with an insulinogenic effect following ingestion of oral glucose, known as the incretin effect [28]. The role of GIP in the development of diabetes and obesity is unclear, but hyperglycaemia may act to directly down-regulate GIP receptors in pancreatic b-cells leading to a defect in late-stage insulin release. GIP is also thought to have significant effects on fatty acid metabolism through stimulation of lipoprotein lipase activity in adipocytes [29]. RYGB is found in some studies to cause a reduction in postprandial GIP secretion due to the restriction of nutrient passage through the duodenum and jejunum, and this effect may be enhanced in patients with type 2 diabetes mellitus (T2DM) [30-32]. Bunt et al. assessed the effects of a mixed-meal test following GB and RYGB and found statistically significant lower GIP levels in the RYGB group [33]. The RYGB group had increased GIP levels postsurgically whereas there were no observed changes in the GB group. Similar findings have been reported by others after GB [34]. The effects of SG on GIP regulation have not been studied sufficiently.

\section{Glucagon-Like Peptide 1}

GLP-1 is a 30-amino acid-long peptide hormone deriving from the tissue-specific posttranslational processing of the proglucagon gene. It is produced and secreted by intestinal enteroendocrine L-cells and certain neurones within the nucleus of the solitary tract in the brainstem upon food consumption. Alongside GIP, GLP-1 is the only known incretin describing its ability to decrease blood sugar levels in a glucose-dependent manner by enhancing the secretion of insulin. Beside the insulinotropic effects, GLP-1 has been associated with numerous regulatory and protective effects. Despite the lack of evidence indicating increased GLP-1 concentrations following bariatric surgery [35], postprandial GLP-1 levels are increased following GB, SG and RYGB $[36,37]$. It is not fully understood why there is increase in GLP-1 postsurgery, but it is believed that it may be associated to the passage of more intact nutrients to the ileum through anatomical changes or increased intestinal transit [25, 38]. Others suggest that bypassing the upper small intestine may be responsible for the beneficial effect of bariatric surgery [39, 40]. Supporting evidence for the importance of the GLP-1 system comes from acute human experiments in which GLP-1 antagonists are administered to humans after an RYGB and appear to reduce the enhanced insulin secretion that occurs after the procedure $[41 \bullet \bullet, 42 \cdot]$. However, in genetic loss-of-function experiments, where mice lack the only identified receptor for GLP-1, both vertical sleeve gastrectomy (VSG) and RYGB have identical effects on both weight loss and glucose improvements compared with the effects in wildtype mice, implying that activation of the GLP-1 receptor does not contribute to the benefits of VSG and RYGB [43, 44•]. GLP-1 agonists or mimetics such as liraglutide, exenatide or lixisenatide have been approved for pharmacological use in the treatment of diabetes and obesity [45, 46]. GLP-1 is also thought to have centrally mediated effects upon appetite by interacting with vagal afferent nerve fibres. In rodents, GLP-1 administration appears to activate neurones in the arcuate nucleus and paraventricular nucleus to promote satiety [47-50]. Performing a vagotomy with bariatric surgery attenuates these effects [48]. There is also some evidence to support an increase in energy expenditure in rodents [50], but this has not been replicated in humans. Dirksen et al. showed that levels of 
GLP-1 were higher in patients who lost more weight, compared to those with poor weight loss [21•]. In another study, SG was still effective in GLP-1 receptor knockout mice, suggesting that alternative pathways must also be involved [51]. Mokadem et al. revealed that RYGB had beneficial metabolic effects in two GLP-1 KO mouse models, similar to RYGBtreated control mice [52•]. Although GLP-1-induced incretin effect might be in part responsible for the improved glucose tolerance after bariatric surgery, increased insulin secretion might be expected to produce weight gain, rather than weight loss. The weight loss-induced effect of GLP-1 following bariatric surgery remains poorly understood.

\section{Glucagon-Like Peptide 2}

Glucagon-like peptide 2 (GLP-2) is a 33-amino acid peptide created by specific posttranslational proteolytic cleavage of proglucagon in a process that also liberates the related GLP1. GLP-2 is produced by the intestinal endocrine L cell and by various neurones in the central nervous system. Intestinal GLP-2 is co-secreted along with GLP-1 upon nutrient ingestion. GLP-2 appears to have a role in stimulating gut hypertrophy by ileal cell hyperplasia and reducing apoptosis and has been used therapeutically in patients with short gut syndrome [53, 54]. There are various studies assessing the effects of RYGB on GLP-2 regulation. Taqi et al., in an experimental study, demonstrated a significant increase in the GLP-2 levels after gastric bypass in rats [55]. LeRoux et al., in a human prospective study, demonstrated a significant increase in the postprandial levels of GLP-2 after gastric bypass, with a secretion peak observed 6 months after the procedure [56]. Cazzo et al., in a human prospective study, observed a significant increase in the GLP-2 levels 12 months after surgery and demonstrated that this increase was significantly correlated with aspects of satiety regulation [57]. Comparing individuals who underwent gastric bypass and SG, Romero et al. observed in a prospective study that both procedures led to a significant increase in the postprandial levels of GLP-2 6 weeks after surgery, without significant difference between the two evaluated procedures [58]. Cummings et al., in an experimental study, demonstrated a significant increase in the GLP-2 levels in rats after the SG [59•]. Evidence suggests that GLP-2 postoperatively increases, and this change may be potentially related to weight loss stabilization, late reduction of diarrhoea and malabsorption, partial compensation of harms to bone mineral metabolism, minimization of the consequences of bacterial overgrowth and regulation of specific aspects of satiety regulation.

\section{Pancreatic Peptide YY}

Peptide YY (PYY) also known as pancreatic peptide YY3-36 is a peptide that in humans is encoded by the PYY gene. PYY is a short (36-amino acid) peptide released by $\mathrm{L}$ enteroendocrine cells in the distal small intestine and colon in response to feeding. Following cleavage in the circulation by the enzyme dipeptidylpeptidase-IV (DPP-IV), PYY1-36 is converted to PYY3-36, suspected to promote satiety through its agonism of the Y2 receptor [60, 61]. PYY3-36 has many effects, including delaying gastric emptying, reducing postprandial insulin production and altering colonic motility, but its main role appears to involve the central regulation of appetite [60-63]. Le Roux et al. were able to demonstrate that obese individuals had reduced postprandial PYY3-36 levels and individuals infused with PYY3-36 demonstrated reduced food intake [64•]. Levels of PYY3-36 appear to increase postprandially following bariatric surgery [65••]. PYY3-36 levels increase postprandially regardless of bariatric procedure $[37,65 \bullet \bullet, 66 \bullet$. In rodent KO models, PYY appears to have an important role to weight loss following bypass surgery [25, 67]. Further research and innovative approaches are required to better understand PYY (336) physiology, its role in obesity and bariatric surgery and therapeutic potential.

\section{Oxyntomodulin}

Oxyntomodulin originates from the proglucagon gene by alternative posttranslational processing pathways. It is a naturally occurring 37-amino acid peptide structurally similar to glucagon with an additional C-terminal octapeptide. Oxyntomodulin is produced by the $\mathrm{L}$ cells in the colon and has been found to suppress appetite. The mechanism of action of oxyntomodulin is not well understood. It is known to bind both the GLP-1 receptor and the glucagon receptor, but it is not known whether the effects of the hormone are mediated through these receptors or through an unidentified receptor. Oxyntomodulin regulation following bariatric surgery is poorly understood, and very few studies have looked at the effects of surgery on oxyntomodulin. In one study, ten obese women with T2DM who had RYGB were matched with ten women who achieved 10-kg weight loss through diet. The group who underwent RYGB had increased oxyntomodulin levels following a mixed-meal test that were correlated to circulated GLP-1 and PYY levels [68•]. These findings have been replicated by others [69••]. Exogenous administration of oxyntomodulin in mice leads to body weight loss, increased energy expenditure and amplified glucoseinduced insulin secretion $[70 \bullet, 71]$. No specific receptor for oxyntomodulin has yet been identified, and because oxyntomodulin lacks the ability to increase insulin secretion in GLP-1R-/- mice, this effect of oxyntomodulin can likely be attributed to its action on GLP-1R. Subcutaneous 
oxyntomodulin infusions reduce body weight in rodents [70 • and humans by increasing energy expenditure and reducing food intake [72••, 73].

\section{Secretin}

Secretin is a 27 -amino acid peptide hormone which is produced by $\mathrm{S}$ cells in the duodenal mucosa in response to a low intraluminal $\mathrm{pH}$, inhibiting the secretion of gastric acid from the parietal cells of the stomach and stimulating the production of bicarbonate from the centroacinar cells and intercalated ducts of the pancreas. It also stimulates bile production by the liver; the bile emulsifies dietary fats in the duodenum so that pancreatic lipase can act upon them. In humans, the secretin peptide is encoded by the SCT gene [74]. Rhee et al. studied the impact of Roux-en-Y gastric bypass (RYGB) on the density and hormonal gene expression of small-intestinal enteroendocrine cells in obese patients with type 2 diabetes. Twelve patients with diabetes and 11 age- and BMI-matched controls underwent RYGB followed by enteroscopy $\sim 10$ months later. Mucosal biopsies taken during surgery and enteroscopy were immunohistochemically stained for secretin and secretin mRNA was reduced after RYGB [75•]. In another study, 18 patients without T2DM had perianastomotic jejunal biopsies at baseline and using endoscopy 12 months postoperatively. RYGB had no impact on villi length or density of secretin [76]. Changes in secretin homeostasis have not been studied following GB or SG.

\section{Vasoactive Intestinal Polypeptide}

Vasoactive intestinal polypeptide (VIP) is a neuropeptide of 28-amino acid residues that belongs to a glucagon/secretin superfamily, the ligand of class II G protein-coupled receptors, and is released by the enteric-neural system and parasympathetic efferent nerve fibres. It acts to increase the secretion of water and electrolytes into the pancreatic juices and the gut itself. VIP stimulates contractility in the heart, causes vasodilation, increases glycogenolysis, lowers arterial blood pressure and relaxes the smooth muscle of trachea, stomach and gall bladder. In humans, VIP is encoded by the VIP gene [77]. The effects of bariatric surgery on VIP regulation remain elusive.

\section{Pancreatic Polypeptide}

Pancreatic polypeptide is a polypeptide secreted by pancreatic polypeptide (PP) cells in the endocrine pancreas predominantly in the head of the pancreas. It consists of 36 amino acids. The function of PP is to self-regulate pancreatic secretion activities (endocrine and exocrine); it also has effects on hepatic glycogen levels and gastrointestinal secretions. Its secretion in humans is increased after a protein meal, fasting, exercise and acute hypoglycaemia and is decreased by somatostatin and intravenous glucose [78]. Dixon et al. examined 17 postoperative individuals who had already achieved a mean of $28 \%$ GB-induced weight loss (range, 10-38\%) whilst taking part in a cross-sectional study and 16 obese individuals prior to GB from a prospective study and assessed plasma PP and PYY meal responses. They concluded that PP responses appeared unchanged by weight loss status but a reduced PP meal response may predict higher weight loss [79].

\section{Insulin}

Insulin is a 51 -amino acid peptide hormone produced by beta cells of the pancreatic islets. It regulates the metabolism of carbohydrates, fats and protein by promoting the absorption of, especially, glucose from the blood into fat, liver and skeletal muscle cells. Accumulating evidence suggests that $\beta$-cell function can be improved early after RYGB and SG. In glucose-tolerant individuals, the insulin response to a mixed meal is decreased after weight loss resulting from GB, SG or RYGB, Specifically, the profile of the insulin curve shifts to a more rapid response and a steeper fall after SG and RYGB, whereas the insulin curve after GB is characterized by a parallel downshift of the insulin concentration $[7 \bullet, 80 \bullet \bullet, 81 \bullet, 82 \bullet]$. The different profiles are probably caused by the different rates of glucose absorption and especially the different GLP1 response profiles $[7 \bullet, 80 \bullet \cdot$. In cases of type 2 diabetes, only minor changes in insulin profile have been reported after GB, whereas after SG or RYGB, an improved initial insulin response has been described that is reminiscent of that in glucose-tolerant obese people [83•]. B-cell glucose sensitivity increases a few days after SG or RYGB, thus improving the dynamic responsiveness during a meal, whereas the responsiveness to intravenous glucose stimulation is unchanged during the first few months after surgery [82•, 83•]. Additionally, insulin sensitivity also improves after bariatric surgery. Regardless of the type of operation, hepatic insulin sensitivity is improved within days after the procedure, presumably due to caloric restriction. Following major weight loss occurring after several months postsurgically, insulin sensitivity is also improved in individual cases [82•, 83•]. Weight loss effect therefore, appears to have a catalytic role regarding the magnitude of improvement in skeletal muscle insulin sensitivity. Of patients following RYGB, SG and GB, respectively, 1, 4 and $31 \%$ have unchanged glucose tolerance [84]. Bariatric surgery also reduces the likelihood of progression to T2DM compared to matched controls [85••].

\section{Obestatin}

Obestatin is a hormone that is produced in specialized epithelial cells of the stomach and small intestine of several mammals including humans. Obestatin was originally identified as an anorectic peptide, but its effect on food intake remains 
controversial [86]. Obestatin is encoded by the same gene that encodes ghrelin, a peptide hormone. Ghrelin is cleaved to produce proghrelin which is cleaved to produce a 28 -amino acid ghrelin (unacylated) and C-ghrelin(acylated). Obestatin is presumed to be cleaved from C-ghrelin [87]. Zhou et al. were able to demonstrate increased obestatin and ghrelin/obestatin ratio in mice treated with RYGB whereas obestatin was decreased in the SG group [25]. In a human study, Siejka et al. were unable to demonstrate significant changes in obestatin levels post-SG [88]. In contrast to ghrelin, which acts as an appetite stimulant, treatment of rodents with obestatin suppresses food intake, inhibits jejunal contractions and decreases body weight [89]. Only a few studies on obestatin levels in human obesity have been published. Plasma obestatin levels are significantly lower in obese subjects, as compared to lean controls, indicating a role for obestatin in long-term body weight regulation, and decreased obestatin levels were reported in morbidly obese subjects referred to bariatric surgery.

\section{Gustducin}

Whilst gustducin was known to be expressed in some taste receptor cells (TRCs), studies with rats showed that gustducin was also present in a limited subset of cells lining the stomach and intestine. These cells appear to share several features of TRCs [90]. Recent rodent studies have found functional intestinal nutrient sensing through $\alpha$-gustducin in the gut in relation to GLP-1 secretion after RYGB [52•]. Under normal circumstances, T1r3 sweet taste receptors on the L cells are coupled to the $G$ protein $\alpha$-subunit $\alpha$-gustducin. Activation of this pathway stimulates GLP-1 secretion. As a result, $\alpha$-gustducin-l- knockout mice, similar to GLP-1R KO, are considered a functional knockout of GLP-1 signalling [52•]. In another rodent study, the role of $\alpha$-gustducin in the RYGB-induced improvement of glucose homeostasis could not be clearly assessed by Steensels et al. as sham-operated $\alpha$-gust $K O$ mice displayed better glucose profiles and tended to display lower insulin levels compared to sham-operated wildtype (WT) mice [91]. These results indicate that $\alpha$-gust $K O$ mice were partially protected from the diabetogenic properties of a western style diet. Avau et al. previously showed that high-fat diet-induced obese $\alpha$-gust KO mice have an increased heat production compared to WT mice, as a result of an increased brown adipose tissue thermogenic activity [92]. Finally, $\alpha$-gustducin stimulates the expression of sodium glucose transporter and Glut 2 receptor, and activation of $\alpha$-gustducin may be correlated to the hyperabsorption observed during an oral glucose tolerance test following bariatric surgery [93].

\section{Somatostatin}

Somatostatin is a peptide hormone that regulates the endocrine system and affects neurotransmission and cell proliferation via interaction with $G$ protein-coupled somatostatin receptors and inhibition of the release of numerous secondary hormones. Somatostatin inhibits insulin and glucagon secretion. Somatostatin is a peptide hormone produced by delta (or D) cells in the pancreas, stomach and duodenum. The pre-prohormone can be cleaved at two different locations giving two forms of 14 and 28 amino acids in length, which both have biological activity. In the gastrointestinal tract, it reduces the secretion of gastrin, secretin, CCK, GIP and GLP-1. In the pituitary, it reduces the secretion of growth hormone, thyroid-stimulating hormone and prolactin. In the pancreas, it reduces the production and secretion of insulin and glucagon and inhibits exocrine secretion. A somatostatin analogue with high biding affinity to somatostatin receptor 2 and lower to 3 and 5 (sstr 2,3,5), octreotide, has caused reduced adiposity in high-fat-fed rats [94]. Somatostatin infusion in a study of obese women inhibited release of PYY [95]. Despite the previous, the role of somatostatin following bariatric surgery remains poorly characterized.

\section{Glucagon}

Glucagon is a 29-amino acid peptide hormone produced in the alpha cells of the pancreatic islets of Langerhans, which are located in the endocrine portion of the pancreas. Its production is suppressed/regulated by insulin from the adjacent beta cells. Glucagon is also released during the fasting state and acts to increase blood sugar levels by promoting glycogenolysis and gluconeogenesis. Very few studies have assessed the effect of bariatric surgery upon circulating glucagon concentrations. Farey et al. demonstrated a significant reduction in glucagon levels 3 months post-SG [96]. Korner et al. assessed women after GB and RYGB and in a group of overweight control patients ( $n=36$ in total) for glucagon concentrations. The investigators found no difference in glucagon levels between groups following a mixed-meal test, except for $180 \mathrm{~min}$ after the test was commenced where patients who had the RYGB compared to the control group had significantly lower glucagon levels [97]. Umeda et al. assessed glucagon concentrations at baseline and 3 months after RYGB. According to their observations, fasting glucagon concentrations increased and postprandial glucagon levels decreased following surgery in response to a liquid meal [98].

\section{Fibroblast Growth Factors (FGF19,21)}

Fibroblast growth factors (FGFs) constitute a family of proteins comprising at least 22 members involved in the regulation of cell growth and differentiation, development, angiogenesis, 
wound repair and metabolism [99]. Most FGFs are secreted heparin-binding proteins and function as autocrine or paracrine factors, whilst FGF19, FGF21 and FGF23 exhibit common unique structural properties which confer them the ability to elicit endocrine actions functioning as hormones. FGF19 is an ileum-derived enterokine that controls bile acid and nutrient metabolism. FGF19 has been reported to play a role in the regulation of glucose and lipid metabolism, as well as in energy expenditure and body adiposity [99]. FGF21 is produced mainly in the liver and promotes fatty acid oxidation, improves insulin sensitivity and increases energy expenditure [99]. FGF21 is paradoxically increased in obesity, suggesting that obesity is a FGF21-resistant state [99]. Gomez-Ambrosi et al. were able to demonstrate that FGF19 levels in obese patients increase after bariatric surgery-induced weight loss regardless of the surgical procedure used, but not after diet-induced weight loss [100]. They were also able to demonstrate that FGF21 concentrations in obese patients decrease after diet- and SGinduced weight loss, but not after weight loss following RYGB [100]. Martinez de la Escalera et al. investigated 39 obese women with T2DM who underwent various bariatric procedures and were able to demonstrate that changes in circulating FGF19 levels were surgery specific [101].

\section{Conclusions}

Whether the metabolic benefits of bariatric surgery are secondary to weight loss or not remains controversial. It is nevertheless clear that there are widespread physiological responses to changes in GI tract morphology. Studies of peptide hormone concentrations after bariatric surgery have often found conflicting results, and these findings are further complicated by the fact that most of the observed hormonal and physiological responses are similar between all surgical interventions. Weight loss itself can cause changes in gut hormone secretion, regardless of the effects of bariatric surgery, making it difficult to evaluate the independent effects of surgery on weight loss postsurgically. The beneficial effects of bariatric surgery are still poorly understood, but are most likely to be multifactorial in aetiopathogenesis. An obvious candidate, however, is GLP-1. The increase in postprandial GLP-1 levels following bariatric surgery is obviously beneficial to the stimulation of postprandial insulin secretion. Interestingly, however, suppression of the GLP-1R does not diminish the beneficial effects of surgery, indicating that this is not the only mechanism for the observed metabolic phenomena of surgery. Changes in calorie restriction occurring postsurgery, coupled with hormonal adaptations, promote weight loss which, surprisingly, can be preserved in the long term. Yet, there are patients lacking sustainable weight loss despite initial good response to bariatric surgery (secondary poor responders). There are several hypotheses regarding this phenomenon, including cognitive traits related to eating behaviour and isolated cases of blunted GLP-1 and PYY secretion following bariatric surgery. In contrast, primary poor responders to bariatric surgery may be genetically predisposed to a limited weight loss as various genome-wide associated studies have shown. In such cases, weight loss \% over time is a strong prognostic factor to overall achieved weight loss.

The success of bariatric surgery comes from the combined effect of physiological and molecular signalling changes in both the GI tract and other organs that result in sustained weight loss and improved glucose and insulin homeostasis.

Acknowledgements We acknowledge the scientific input from Professor Harpal S. Randeva in the design of this manuscript.

\section{Compliance with Ethical Standards}

Conflict of Interest Georgios K. Dimitriadis, Manpal S. Randeva and Alexander D. Miras declare they have no conflict of interest.

Human and Animal Rights and Informed Consent This article does not contain any studies with human or animal subjects performed by any of the authors.

Open Access This article is distributed under the terms of the Creative Commons Attribution 4.0 International License (http:// creativecommons.org/licenses/by/4.0/), which permits unrestricted use, distribution, and reproduction in any medium, provided you give appropriate credit to the original author(s) and the source, provide a link to the Creative Commons license, and indicate if changes were made.

\section{References}

Papers of particular interest, published recently, have been highlighted as:

- Of importance

•. Of major importance

1. Finucane MM, Stevens GA, Cowan MJ, et al. National, regional, and global trends in body-mass index since 1980: systematic analysis of health examination surveys and epidemiological studies with 960 country-years and 9.1 million participants. Lancet. 2011;377:557-67.

2. Cavin JB, Bado A, Le Gall M. Intestinal adaptations after bariatric surgery: consequences on glucose homeostasis. Trends Endocrinol Metab. 2017;28(5):354-64.

3. Evers SS, Sandoval DA, Seeley RJ. The physiology and molecular underpinnings of the effects of bariatric surgery on obesity and diabetes. Annu Rev Physiol. 2017;79:313-34.

4. Sharples AJ, Charalampakis V, Daskalakis M, Tahrani AA, Singhal R. Systematic review and meta-analysis of outcomes after revisional bariatric surgery following a failed adjustable gastric band. Obes Surg. 2017; doi:10.1007/s11695-017-2677-7.

5. Golzarand M, Toolabi K, Farid R. The bariatric surgery and weight losing: a meta-analysis in the long- and very long-term effects of laparoscopic adjustable gastric banding, laparoscopic Roux-en-Y gastric bypass and laparoscopic sleeve gastrectomy 
on weight loss in adults. Surg Endosc. 2017; doi:10.1007/s00464017-5505-1.

6. Magouliotis DE, Tasiopoulou VS, Svokos AA, Svokos KA, Sioka E, Zacharoulis D. Roux-en-Y gastric bypass versus sleeve gastrectomy as revisional procedure after adjustable gastric band: a systematic review and meta-analysis. Obes Surg. 2017;27(5):136573.

7. Jacobsen SH, Olesen SC, Dirksen C, Jørgensen NB, BojsenMøller KN, Kielgast U, et al. Changes in gastrointestinal hormone responses, insulin sensitivity, and beta-cell function within 2 weeks after gastric bypass in non-diabetic subjects. Obes Surg. 2012;22(7):1084-96. A detailed analysis of the early hormone changes after RYGB in response to three different oral test meals

8. Sundbom M, Holdstock C, Engström BE, Karlsson FA. Early changes in ghrelin following Roux-en-Y gastric bypass: influence of vagal nerve functionality ? Obes Surg. 2007;17(3):304-10.

9. Safatle-Ribeiro AV, Petersen PA, Pereira Filho DS, Corbett CE, Faintuch J, Ishida R, et al. Epithelial cell turnover is increased in the excluded stomach mucosa after Roux-en-Y gastric bypass for morbid obesity. Obes Surg. 2013;23(10):1616-23.

10. Hedberg J, Hedenström H, Nilsson S, Sundbom M, Gustavsson S. Role of gastric acid in stomal ulcer after gastric bypass. Obes Surg. 2005;15(10):1375-8.

11. Grong E, Græslie H, Munkvold B, Arbo IB, Kulseng BE, Waldum $\mathrm{HL}$, et al. Gastrin secretion after bariatric surgery-response to a protein-rich mixed meal following Roux-en-Y gastric bypass and sleeve gastrectomy: a pilot study in normoglycemic women. Obes Surg. 2016 Jul;26(7):1448-56.

12. Shak JR, Roper J, Perez-Perez GI, Tseng CH, Francois F, Gamagaris Z, et al. The effect of laparoscopic gastric banding surgery on plasma levels of appetite-control, insulinotropic, and digestive hormones. Obes Surg. 2008;18(9):1089-96.

13. Sillakivi T, Suumann J, Kirsimägi U, Peetsalu A. Plasma levels of gastric biomarkers in patients after bariatric surgery: biomarkers after bariatric surgery. Hepato-Gastroenterology. 2013;60(128): 2129-32.

14. Grong E, Arbo IB, Thu OK, Kuhry E, Kulseng B, Mårvik R. The effect of duodenojejunostomy and sleeve gastrectomy on type 2 diabetes mellitus and gastrin secretion in Goto-Kakizaki rats. Surg Endosc. 2015;29(3):723-33.

15. Dickson SL, Egecioglu E, Landgren S, Skibicka KP, Engel JA, Jerlhag E. The role of the central ghrelin system in reward from food and chemical drugs. Mol Cell Endocrinol. 2011;340(1):80 7. doi:10.1016/j.mce.2011.02.017. Recent advances that identify a role for the central ghrelin signalling system in reward from both natural rewards (such as food) and artificial rewards (that include alcohol and drugs of abuse)

16. Burger KS, Berner LA. A functional neuroimaging review of obesity, appetitive hormones and ingestive behaviour. Physiol Behav. 2014;136:121-7. doi:10.1016/j.physbeh.2014.04.025.

17. Delhanty PJ, van der Lely AJ. Ghrelin and glucose homeostasis. Peptides. 2011;32(11):2309-18.

18. Cummings DE, Weigle DS, Frayo RS, Breen PA, Ma MK, Dellinger EP, et al. Plasma ghrelin levels after diet-induced weight loss or gastric bypass surgery. N Engl J Med. 2002;346(21):162330. 24-hour plasma ghrelin profiles, body composition, insulin levels, leptin levels, and insulin sensitivity in 13 obese subjects before and after a six-month dietary program for weight loss

19. Frühbeck G, Rotellar F, Hernández-Lizoain JL, Gil MJ, GómezAmbrosi J, Salvador J, et al. Fasting plasma ghrelin concentrations 6 months after gastric bypass are not determined by weight loss or changes in insulinemia. Obes Surg. 2004;14(9):1208-15.

20. Frühbeck G, Diez-Caballero A, Gil MJ, Montero I, GómezAmbrosi J, Salvador J, et al. The decrease in plasma ghrelin concentrations following bariatric surgery depends on the functional integrity of the fundus. Obes Surg. 2004;14(5):606-12.

21. Dirksen C, Jørgensen NB, Bojsen-Møller KN, Kielgast U, Jacobsen SH, Clausen TR, et al. Gut hormones, early dumping and resting energy expenditure in patients with good and poor weight loss response after Roux-en-Y gastric bypass. Int J Obes. 2013;37(11):1452-9. Cross-sectional study of patients with good (excess body mass index lost $(\mathrm{EBL})>60 \%$ ) and poor weight loss response (EBL $<50 \%)>12$ months after RYGB and a lean control group matched for age and gender

22. Yang J, Feng X, Zhong S, Wang Y, Liu J. Gastric bypass surgery may improve beta cell apoptosis with ghrelin overexpression in patients with BMI $\geq 32.5 \mathrm{~kg} / \mathrm{m} 2$. Obes Surg. 2014;24(4):561-71.

23. Zhou D, Jiang X, Ding W, Zhang D, Yang L, Zhen C, et al. Impact of bariatric surgery on ghrelin and obestatin levels in obesity or type 2 diabetes mellitus rat model. J Diabetes Res. 2014;2014: 569435.

24. Yousseif A, Emmanuel J, Karra E, Millet Q, Elkalaawy M, Jenkinson AD, et al. Differential effects of laparoscopic sleeve gastrectomy and laparoscopic gastric bypass on appetite, circulating acylghrelin, peptide YY3-36 and active GLP-1 levels in nondiabetic humans. Obes Surg. 2014;24(2):241-52.

25. Steinert RE, Feinle-Bisset C, Asarian L, Horowitz M, Beglinger C, Ghrelin GN. CCK, GLP-1, and PYY(3-36): secretory controls and physiological roles in eating and glycemia in health, obesity, and after RYGB. Physiol Rev. 2017;97(1):411-63.

26. Mans E, Serra-Prat M, Palomera E, Suñol X, Clavé P. Sleeve gastrectomy effects on hunger, satiation, and gastrointestinal hormone and motility responses after a liquid meal test. Am J Clin Nutr. 2015;102(3):540-7.

27. Peterli R, Steinert RE, Woelnerhanssen B, Peters T, ChristoffelCourtin C, Gass M, et al. Metabolic and hormonal changes after laparoscopic Roux-en-Y gastric bypass and sleeve gastrectomy: a randomized, prospective trial. Obes Surg. 2012;22(5):740-8. The mechanisms of amelioration of glycemic control early after laparoscopic Roux-en-Y gastric bypass (LRYGB) or laparoscopic sleeve gastrectomy (LSG)

28. McIntosh CH, Widenmaier S, Kim SJ. Glucose-dependent insulinotropicpolypeptide (gastric inhibitory polypeptide; GIP). Vitam Horm. 2009;80:409-71.

29. Piteau S, Olver A, Kim SJ, Winter K, Pospisilik JA, Lynn F, et al. Reversal ofislet GIP receptor down-regulation and resistance to GIP by reducing hyperglycemia in the Zucker rat. Biochem Biophys Res Commun. 2007;362(4):1007-12.

30. Guidone C, Manco M, Valera-Mora E, Iaconelli A, Gniuli D, Mari A, et al. Mechanisms of recovery from type 2 diabetes after malabsorptive bariatric surgery. Diabetes. 2006;55(7):2025-31.

31. Mingrone G, Nolfe G, Gissey GC, Iaconelli A, Leccesi L, Guidone C, et al. Circadian rhythms of GIP and GLP1 in glucose-tolerant and in type 2 diabetic patients after biliopancreatic diversion. Diabetologia. 2009;52(5):873-81.

32. Salinari S, Bertuzzi A, Asnaghi S, Guidone C, Manco M, Mingrone G. First-phase insulin secretion restoration and differential response to glucose load depending on the route of administration in type 2 diabetic subjects after bariatric surgery. Diabetes Care. 2009;32(3):37580 .

33. Bunt JC, Blackstone R, Thearle MS, Vinales KL, Votruba S, Krakoff J. Changes in glycemia, insulin and gut hormone responses to a slowly ingested solid low-carbohydrate mixed meal after laparoscopic gastric bypass or band surgery. Int J Obes. 2017;41(5):706-13.

34. Korner J, Bessler M, Inabnet W, Taveras C, Holst JJ. Exaggerated glucagon-like peptide-1 and blunted glucose-dependent insulinotropic peptide secretion are associated with Roux-en-Y gastric bypass but not adjustable gastric banding. Surg Obes Relat Dis. 2007;3(6):597-601. 
35. Evans S, Pamuklar Z, Rosko J, Mahaney P, Jiang N, Park C, et al. Gastric bypass surgery restores meal stimulation of the anorexigenic gut hormones glucagon-like peptide-1 and peptide YY independently of caloric restriction. Surg Endosc. 2012;26(4):108694.

36. Shankar SS, Mixson LA, Chakravarthy M, Chisholm R, Acton AJ, Jones R, et al. Metabolic improvements following Roux-en-Y surgery assessed by solid meal test in subjects with short duration type 2 diabetes. BMC Obes. 2017;4:10.

37. Tsoli M, Chronaiou A, Kehagias I, Kalfarentzos F, Alexandrides TK. Hormone changes and diabetes resolution after biliopancreatic diversion and laparoscopic sleeve gastrectomy: a comparative prospective study. Surg Obes Relat Dis. 2013;9(5): 667-77.

38. Nausheen S, Shah IH, Pezeshki A, Sigalet DL, Chelikani PK. Effects of sleeve gastrectomy and ileal transposition, alone and in combination, on food intake, body weight, gut hormones, and glucose metabolism in rats. Am J Physiol Endocrinol Metab. 2013;305(4):E507-18.

39. Rubino F, Marescaux J. Effect of duodenal-jejunal exclusion in a non-obese animal model of type 2 diabetes: a new perspective for an old disease. Ann Surg. 2004;239(1):1-11.

40. Pacheco D, de Luis DA, Romero A, González Sagrado M, Conde $\mathrm{R}$, Izaola $\mathrm{O}$, et al. The effects of duodenal-jejunal exclusion on hormonal regulation of glucose metabolism in Goto-Kakizaki rats. Am J Surg. 2007;194(2):221-4.

41.• Jørgensen NB, Dirksen C, Bojsen-Møller KN, Jacobsen SH, Worm D, et al. Exaggerated glucagon-like peptide 1 response is important for improved beta-cell function and glucose tolerance after Roux-en-Y gastric bypass in patients with type 2 diabetes. Diabetes. 2013;62:3044-52. The exaggerated effect of GLP-1 after RYGB is of major importance for the improvement in $\beta$ cell function, control of glucagon release, and glucose tolerance in patients with type 2 diabetes

42. Holst JJ. Postprandial insulin secretion after gastric bypass surgery: the role of glucagon-like peptide 1. Diabetes. 2011;60: 2203-5. Antidiabetic actions of endogenous and exogenous GLP-1 in type 1 diabetic patients with and without residual $\beta$ cell function. Gastric bypass surgery enhances glucagon-like peptide 1 stimulated postprandial insulin secretion in humans

43. Ye J, Hao Z, Mumphrey MB, Townsend RL, Patterson LM, et al. GLP-1 receptor signaling is not required for reduced body weight after RYGB in rodents. Am J Physiol Regul Integr Comp Physiol. 2014;306:R352-62.

44. Wilson-P'erez HE, Chambers AP, Ryan KK, Li B, Sandoval DA, et al. Vertical sleeve gastrectomy is effective in two genetic mouse models of glucagon-like peptide 1 receptor deficiency. Diabetes. 2013;62:2380-5. VSG-operated GLP-1 receptor-deficient mice respond similarly to wild-type controls in terms of body weight and body fat loss, improved glucose tolerance, food intake reduction, and altered food selection, demonstrating that GLP-1 receptor activity is not necessary for the metabolic improvements induced by VSG surgery

45. Vilsbøll T, Zdravkovic M, Le-Thi T, Krarup T, Schmitz O, Courrèges JP, et al. Liraglutide, a long-acting human glucagonlike peptide-1 analog, given as monotherapy significantly improves glycemic control and lowers bodyweight without risk of hypoglycemia in patients with type 2 diabetes. Diabetes Care. 2007;30(6):1608-10.

46. Wadden TA, Hollander P, Klein S, Niswender K, Woo V, Hale $\mathrm{PM}$, et al. Weight maintenance and additional weight loss with liraglutide after low-calorie-diet-induced weight loss: the SCALE Maintenance randomized study. Int J Obes. 2013;37(11):1443-51

47. Abbott CR, Monteiro M, Small CJ, Sajedi A, Smith KL, Parkinson JR, et al. The inhibitory effects of peripheral administration of peptide YY(3-36) and glucagon-like peptide-1 on food intake are attenuated by ablation of the vagal-brainstemhypothalamic pathway. Brain Res. 2005;1044(1):127-31.

48. Larsen PJ, Tang-Christensen M, Jessop DS. Central administration of glucagon-like peptide-1 activates hypothalamic neuroendocrine neurons in the rat. Endocrinology. 1997;138(10):444555 .

49. Turton MD, O'Shea D, Gunn I, Beak SA, Edwards CM, Meeran $\mathrm{K}$, et al. A role for glucagon-like peptide- 1 in the central regulation of feeding. Nature. 1996;379(6560):69-72.

50. Bueter M, Miras AD, Chichger H, Fenske W, Ghatei MA, Bloom $\mathrm{SR}$, et al. Alterations of sucrose preference after Roux-en-Y gastric bypass. Physiol Behav. 2011;104(5):709-21.

51. Abalos E, Merialdi M, Wojdyla D, Carroli G, Campodonico L, Yao SE, et al. Effects of calcium supplementation on fetal growth in mothers with deficient calcium intake: a randomised controlled trial. Paediatr Perinat Epidemiol England. 2010;24:53-62.

52. Mokadem M, Zechner JF, Margolskee RF, Drucker DJ, Aguirre V. Effects of Roux-en-Y gastric bypass on energy and glucose homeostasis are preserved in two mouse models of functional glucagon-like peptide-1 deficiency. Mol Metab. 2013;3(2):191201. The effect of RYGB to enhance glucose-stimulated GLP-1 secretion was greatly attenuated in $\alpha$-Gust KO mice. Therefore, GLP-1, acting through its classical GLP-1R or its bioactive metabolites, does not seem to be involved in the effects of RYGB on body weight and glucose homeostasis

53. Estall JL, Drucker DJ. Dual regulation of cell proliferation and survival via activation of glucagon-like peptide-2 receptor signaling. J Nutr. 2003;133(11):3708-11.

54. Martin GR, Wallace LE, Hartmann B, Holst JJ, Demchyshyn L, Toney K, et al. Nutrient-stimulated GLP-2 release and crypt cell proliferation in experimental short bowel syndrome. Am J Physiol Gastrointest Liver Physiol. 2005;288(3):G431-8.

55. Taqi E, Wallace LE, de Heuvel E, Chelikani PK, Zheng H, Berthoud HR, et al. The influence of nutrients, biliary-pancreatic secretions, and systemic trophic hormones on intestinal adaptation in a Roux-en-Y bypass model. J Pediatr Surg. 2010 May;45(5): 987-95.

56. le Roux CW, Borg C, Wallis K, Vincent RP, Bueter M, Goodlad R, et al. Gut hypertrophy after gastric bypass is associated with increased glucagon-like peptide 2 and intestinal crypt cell proliferation. Ann Surg. 2010;252(1):50-6.

57. Cazzo E, Pareja JC, Chaim EA, Geloneze B, Barreto MR, Magro DO. GLP-1 and GLP-2 levels are correlated with satiety regulation after Roux-en-Y gastric bypass: results of an exploratory prospective study. Obes Surg. 2017;27(3):703-8.

58. Romero F, Nicolau J, Flores L, Casamitjana R, Ibarzabal A, Lacy A, et al. Comparable early changes in gastrointestinal hormones after sleeve gastrectomy and Roux-en-Y gastric bypass surgery for morbidly obese type 2 diabetic subjects. Surg Endosc. 2012;26(8): 2231-9.

59. Cummings BP, Bettaieb A, Graham JL, Stanhope KL, Kowala M, Haj FG, et al. Vertical sleeve gastrectomy improves glucose and lipid metabolism and delays diabetes onset in UCD-T2DM rats. Endocrinology. 2012;153(8):3620-32. VSG delays type 2 diabetes onset in the University of California Davis-type 2 diabetes mellitus rat, independent of body weight

60. Batterham RL, Cowley MA, Small CJ, Herzog H, Cohen MA, Dakin CL, et al. Gut hormone PYY(3-36) physiologically inhibits food intake. Nature. 2002;418(6898):650-4.

61. Witte AB, Grybäck P, Holst JJ, Hilsted L, Hellström PM, Jacobsson H, et al. Differential effect of PYY1-36 and PYY3-36 on gastric emptying in man. Regul Pept. 2009;158(1-3):57-62.

62. Wang L, Gourcerol G, Yuan PQ, Wu SV, Million M, Larauche M, et al. Peripheral peptide YY inhibits propulsive colonic motor 
function through Y2 receptor in conscious mice. Am J Physiol Gastrointest Liver Physiol. 2010;298(1):G45-56.

63. Batterham RL, Cohen MA, Ellis SM, Le Roux CW, Withers DJ, Frost GS, et al. Inhibition of food intake in obese subjects by peptide YY3-36. N Engl J Med. 2003;349(10):941-8.

64. le Roux CW, Batterham RL, Aylwin SJ, Patterson M, Borg CM, Wynne KJ, et al. Attenuated peptide YY release in obese subjects is associated with reduced satiety. Endocrinology. 2006;147(1):38. The PYY(3-36) infusion study showed that the degree of plasma PYY reduction in obese subjects were likely associated with decreased satiety and relatively increased food intake

65.• Dirksen C, Bojsen-Møller KN, Jørgensen NB, Jacobsen SH, Kristiansen VB, Naver LS, et al. Exaggerated release and preserved insulinotropic action of glucagon-like peptide-1 underlie insulin hypersecretion in glucose-tolerant individuals after Rouxen-Y gastric bypass. Diabetologia. 2013;56(12):2679-87. After RYGB, insulin hypersecretion is linked to the oral, but not the i.v., route of administration and is associated with exaggerated release and preserved insulinotropic action of GLP-1, while both the secretion and action of GIP are unchanged

66. Korner J, Inabnet W, Febres G, Conwell IM, McMahon DJ, Salas $\mathrm{R}$, et al. Prospective study of gut hormone and metabolic changes after adjustable gastric banding and Roux-en-Y gastric bypass. Int J Obes. 2009;33(7):786-95. Longitudinal study of patients undergoing LAGB $(n=15)$ and RYGB $(n=28)$ who were studied before surgery and at 2, 12, 26 and 52 weeks afterwards

67. Chandarana K, Gelegen C, Karra E, Choudhury AI, Drew ME, Fauveau V, et al. Diet and gastrointestinal bypass-induced weight loss: the roles of ghrelin and peptide YY. Diabetes. 2011;60(3): 810-8.

68. Laferrère B, Swerdlow N, Bawa B, Arias S, Bose M, Oliván B, et al. Rise of oxyntomodulin in response to oral glucose after gastric bypass surgery in patients with type 2 diabetes. J Clin Endocrinol Metab. 2010;95(8):4072-6. Changes in OXM primarily occur in response to GBP and not as a consequence of weight loss

69.•• Falkén Y, Hellström PM, Holst JJ, Näslund E. Changes in glucose homeostasis after Roux-en-Y gastric bypass surgery for obesity at day three, two months, and one year after surgery: role of gut peptides. J Clin Endocrinol Metab. 2011;96(7):2227-35. Enhanced insulin sensitivity and incretin hormones, such as GLP-1, contribute to the early control of glucosehomeostasis post RYGB

70. Pocai A, Carrington PE, Adams JR, Wright M, Eiermann G, Zhu L, et al. Glucagon-like peptide 1/glucagon receptor dual agonism reverses obesity in mice. Diabetes. 2009;58(10):2258-66. GLP1R/GCGR dual agonism reverses obesity in Diet Induced Obese mice and is a novel therapeutic approach to the treatment of obesity

71. Day JW, Ottaway N, Patterson JT, Gelfanov V, Smiley D, Gidda J, et al. A new glucagon and GLP-1 co-agonist eliminates obesity in rodents. Nat Chem Biol. 2009;5(10):749-57.

72.•• Wynne K, Park AJ, Small CJ, Patterson M, Ellis SM, Murphy KG, et al. Subcutaneous oxyntomodulin reduces body weight in overweight and obese subjects: a double-blind, randomized, controlled trial. Diabetes. 2005;54(8):2390-5. Oxyntomodulin treatment results in weight loss and a change in the levels of adipose hormones consistent with a loss of adipose tissue

73. Wynne K, Park AJ, Small CJ, Meeran K, Ghatei MA, Frost GS, et al. Oxyntomodulin increases energy expenditure in addition to decreasing energy intake in overweight and obese humans: a randomised controlled trial. Int J Obes. 2006;30(12):1729-36.

74. Whitmore TE, Holloway JL, Lofton-Day CE, Maurer MF, Chen L, Quinton TJ, et al. Human secretin (SCT): gene structure, chromosome location, and distribution of mRNA. Cytogenet Cell Genet. 2000;90(1-2):47-52.
75. Rhee NA, Wahlgren CD, Pedersen J, Mortensen B, Langholz E, Wandall EP, et al. Effect of Roux-en-Y gastric bypass on the distribution and hormone expression of small-intestinal enteroendocrine cells in obese patients with type 2 diabetes. Diabetologia. 2015;58(10):2254-8. Numerous alterations in the distribution of enteroendocrine cells and their expression of hormonal genes are seen after RYGB and include increased density of GLP-1-, PYY-, CCK-, GIP- and PC2-positive cells, reduced gene expression of GHRL, SCT and GIP and increased expression of GCG

76. Nergård BJ, Lindqvist A, Gislason HG, Groop L, Ekelund M, Wierup N, et al. Mucosal glucagon-like peptide-1 and glucosedependent insulinotropic polypeptide cell numbers in the superobese human foregut after gastric bypass. Surg Obes Relat Dis. 2015;11(6):1237-46.

77. Delgado M, Ganea D. Vasoactive intestinal peptide: a neuropeptide with pleiotropic immune functions. Amino Acids. 2013;45(1):25-39. doi:10.1007/s00726-011-1184-8.

78. Batterham RL, Le Roux CW, Cohen MA, Park AJ, Ellis SM, Patterson M, et al. Pancreatic polypeptide reduces appetite and food intake in humans. J Clin Endocrinol Metab. 2003;88(8): 3989-92. doi:10.1210/jc.2003-030630.

79. Dixon AF, le Roux CW, Ghatei MA, Bloom SR, McGee TL, Dixon JB. Pancreatic polypeptide meal response may predict gastric band-induced weight loss. Obes Surg. 2011;21(12):1906-13.

80.• Bradley D, Conte C, Mittendorfer B, et al. Gastric bypass and banding equally improve insulin sensitivity and $\beta$ cell function. J Clin Invest. 2012;122:4667-74. Weight loss itself is primarily responsible for the therapeutic effects of RYGB and LAGB on insulin sensitivity, $\beta$ cell function, and oral glucose tolerance in non-diabetic obese adults

81. Nannipieri M, Baldi S, Mari A, et al. Roux-en-Y gastric bypass and sleeve gastrectomy: mechanisms of diabetes remission and role of gut hormones. J Clin Endocrinol Metab. 2013;98:43919. RYGB and SLG have a similar impact on diabetes remission, of which baseline $\beta$-cell glucose sensitivity and a restored GLP-1 response are the chief determinants

82. Bojsen-Moller KN, Dirksen C, Jorgensen NB, et al. Early enhancements of hepatic and later of peripheral insulin sensitivity combined with increased postprandial insulin secretion contribute to improved glycemic control after Roux-en-Y gastric bypass. Diabetes. 2013; doi:10.2337/db13-1307. Insulin secretion increases after RYGB in patients with T2D, only in response to oral glucose, underscoring the importance of the changed gut anatomy

83. Camastra S, Muscelli E, Gastaldelli A, et al. Long-term effects of bariatric surgery on meal disposal and b-cell function in diabetic and non-diabetic patients. Diabetes. 2013;62:3709-17. In T2D, bypass surgery changes the postprandial response to a dumping-like pattern and improves glucose tolerance, $\beta$-cell function, and peripheral insulin sensitivity but worsens endogenous glucose output in response to a physiological stimulus

84. Brethauer SA, Aminian A, Romero-Talamás H, Batayyah E, Mackey J, Kennedy L, et al. Can diabetes be surgically cured? Long-term metabolic effectsof bariatric surgery in obese patients with type 2 diabetes mellitus. Ann Surg. 2013;258(4):628-36.

85.• Booth H, Khan O, Prevost T, Reddy M, Dregan A, Charlton J, et al. Incidence of type 2 diabetes after bariatric surgery: population-based matched cohort study. Lancet Diabetes Endocrinol. 2014;2(12):963-8. Bariatric surgery is associated with reduced incidence of clinical diabetes in obese participants without diabetes at baseline for up to 7 years after the procedure

86. Gourcerol G, St-Pierre DH, Taché Y. Lack of obestatin effects on food intake: should obestatin be renamed ghrelin-associated peptide (GAP)? Regul Pept. June 2007;141(1-3):1-7. 
87. Seim I, Amorim L, Walpole C, Carter S, Chopin LK, Herington AC. Ghrelin gene-related peptides: multifunctional endocrine / autocrine modulators in health and disease. Clin Exp Pharmacol Physiol. 2010;37(1):125-31.

88. Siejka A, Jankiewicz-Wika J, Kołomecki K, Cywiński J, Piestrzeniewicz K, Swiętosławski J, et al. Long-term impact of vertical banded gastroplasty (VBG) on plasma concentration of leptin, soluble leptin receptor, ghrelin, omentin-1, obestatin, and retinol binding protein 4 (RBP4) in patients with severe obesity. Cytokine. 2013;64(2):490-3.

89. Huda MS, Durham BH, Wong SP, Deepak D, Kerrigan D, McCulloch P, et al. Plasma obestatin levels are lower in obese and post-gastrectomy subjects, but do not change in response to a meal. Int J Obes. 2008;32:129-35.

90. Margolskee RF. Molecular mechanisms of bitter and sweet taste transduction. J Biol Chem. 2002;277(1):1-4.

91. Steensels S, Lannoo M, Avau B, Laermans J, Vancleef L, Farré R, et al. The role of nutrient sensing in the metabolic changes after gastric bypass surgery. J Endocrinol. 2017;232(3):363-76.

92. Avau B, Bauters D, Steensels S, Vancleef L, Laermans J, Lesuisse $\mathrm{J}$, et al. The gustatory signaling pathway and bitter taste receptors affect the development of obesity and adipocyte metabolism in mice. PLoS One. 2015;10:e145538.

93. Margolskee RF, Dyer J, Kokrashvili Z, Salmon KS, Ilegems E, et al. T1R3 and gustducin in gut sense sugars to regulate expression of Na+-glucose co-transporter 1. PNAS. 2007;104:1507580.

94. Liu R, Wei N, Guo W, Qiang O, Li X, Ou Y, et al. Octreotide alleviates obesity by reducing intestinal glucose absorption and inhibiting low-grade inflammation. Eur J Nutr. 2013;52(3): 1067-75.
95. Rigamonti AE, Cella SG, Bonomo SM, Mancia G, Grassi G, Perotti M, et al. Effect of somatostatin infusion on peptide YY secretion: studies in the acute and recovery phase of anorexia nervosa and in obesity. Eur J Endocrinol. 2011;165(3):421-7.

96. Farey JE, Preda TC, Fisher OM, Levert-Mignon AJ, Stewart RL, Karsten E, et al. Effect of laparoscopic sleeve gastrectomy on fasting gastrointestinal, pancreatic, and adipose-derived hormones and on non-esterified fatty acids. Obes Surg. 2017;27(2):399-407.

97. Korner J, Inabnet W, Conwell IM, Taveras C, Daud A, OliveroRivera L, et al. Differential effects of gastric bypass and banding on circulating guthormone and leptin levels. Obesity (Silver Spring). 2006;14(9):1553-61.

98. Umeda LM, Silva EA, Carneiro G, Arasaki CH, Geloneze B, Zanella MT. Early improvement in glycemic control after bariatric surgery and itsrelationships with insulin, GLP-1, and glucagon secretion in type 2 diabeticpatients. Obes Surg. 2011;21(7):896901.

99. Owen BM, Mangelsdorf DJ, Kliewer SA. Tissue-specific actions of the metabolic hormones FGF15/19 and FGF21. Trends Endocrinol Metab. 2015;26:22e9.

100. Gomez-Ambrosi J, Gallego-Escuredo JM, Catalan V, Rodríguez A, Domingo P, Moncada R, et al. FGF19 and FGF21 serum concentrations in human obesity and type 2 diabetes behave differently after diet- or surgically-induced weight loss. Clin Nutr. 2017;36: $861 \mathrm{e} 868$.

101. de la Martinez Escalera L, Kyrou I, Vrbikova J, Hainer V, Sramkova P, Fried M, et al. Impact of gut hormone FGF-19 on type-2 diabetes and mitochondrial recovery in a prospective study of obese diabetic women undergoing bariatric surgery. BMC Med. 2017;15(1):34. 